\title{
The Scientific Foundation of Disordered Mood
}

The scalpel and microscope will alike fail; the meditations of metaphysicians will come to nought; the disease will remain in its status quo, a phantom and a fear. To the pure doctrine of physiology, we must look for the first glimpse of truth, and by the close application of its principles shall we soonest find the path; while without its help in the study of cerebral disease we shall never attain our end. ${ }^{1}$

J. Hawkes (1855)

In a paper read before the British Association for the Advancement of Science in 1844, physiologist Thomas Laycock described to his audience the case of a young boy who suffered from hydrophobia (a fear of water). He quoted a Mr. Thornhill who had originally published the case in the Medical Gazette:

On suggesting that he should swallow a little water, [the boy] seemed to be frightened, and began to cry out. He turned suddenly in bed, and was simultaneously seized with a momentary clonic spasm of the trunk, greatly resembling emprosthotonos [a spasm in which the head and feet meet and the back is arched]; however, by kindly encouraging him, he soon manifested a willingness to accede my wish, but the sound of the water as it was poured into a teacup, again brought on a similar convulsive action. $^{2}$

Å Jansson, From Melancholia to Depression, Mental Health in Historical Perspective, https://doi.org/10.1007/978-3-030-54802-5_2 
The boy's reaction showed, Laycock argued, that 'the idea of water excites convulsion', proving his thesis that the kind of reflexive model normally reserved for sensory-motor activity also applied to the brain and the mind. In other words, just like involuntary movement could be triggered by sensory stimuli, an abstract idea could act as a trigger for involuntary emotion as well as motor action. While this was at the time a radical idea, it would become one of the most influential and durable psychological principles of the modern period. But how did Laycock arrive at his argument? And what were the implications of such a model of mental operations? This chapter traces the origins of psychological reflex action, the scientific principle that formed the basis for the idea of disordered mood as a medical concept. It begins in the early years of the nineteenth century, when experimental physiology was taking Europe by storm. British scientists such as Marshall Hall and Charles Bell were attempting to describe the functions of the spinal nerves while navigating the gradual and equivocal shift from older ideas about 'sympathy' to a modern framework for physical reactivity. Physiology, the new science of the body with its growing catalogue of empirical evidence, was a goldmine for physicians trying to make sense of and treat the maladies of the mind, and it was rapidly absorbed into medical textbooks for students and practitioners.

The first part of the chapter is concerned with the physiological language of internal medicine from where Laycock drew the analogies used to explain psychological reflexion and, subsequently, disordered emotion. The function of analogous language is central to the emergence of a biomedical language of emotion, and plays a key role in the story of nineteenth-century melancholia more widely. A number of the words used to describe features of melancholia, internal and external, were deployed both as literal descriptions of cerebral (and thus psychological) events, and as analogous to physical processes elsewhere in the body. Moreover, older theories often converged with the new, such as in the work of British physiologist W.B. Carpenter, who embraced a biological reflex model for some mental operations, while insisting on retaining a higher faculty independent from somatic automatism. In sum, biomedical theories of emotion were, at this time, new, fragmented, unsteady, conflicting, and constantly evolving. Nevertheless, within the emerging framework of what became known as physiological psychology, emotion was gradually constituted as a physiological process and a biomedical object of study. As will be seen in later chapters, melancholia was subsequently reconfigured along these new biomedical lines. 


\section{Reflex Action, Automatism, ANd Emotion in Medical Science}

The significant epistemological shifts that occurred in the first decades of the nineteenth century in terms of both scientific and lay perceptions of the natural world and the animal body have been thoroughly explored elsewhere. ${ }^{3}$ What should be noted here is that the physiology of disordered emotion was to a large extent premised upon a belief that the mind could be explained as a manifestation of cerebral activity. Within the wider context of the rise of scientific medicine and secular psychology such beliefs made sense to a vast number of physicians. At the same time, however, materialist conceptions of the relationship between body, brain, mind, and soul were contentious and contested both within and outside scientific communities. For some medical scientists, such as Laycock, subscribing to a physiological model of cerebral activity meant the rejection of a higher, abstract intellect, but for others, most notably Laycock's acquaintance and intellectual rival Carpenter, a separation between soma and psyche was to some extent maintained. There was, as Roger Smith has suggested, 'nothing inevitable about these intellectual developments'. The mind-body problem and the place of humans in the world were questions that pushed at both old and new boundaries of epistemology during the nineteenth century, and there was no clear or simple shift from the Christian to the secular or from the philosophical to the scientific. Rather, 'language often left unresolved a choice between new or old, between a concern with human culture or human science, between a religious or a secular world view. ${ }^{5}$

Nevertheless, physiological experiments performed on frogs and other animals in order to infer knowledge about the human nervous system were premised upon a belief that human beings were inherently part of the animal world and subject to the laws of nature. While humans held a hierarchically superior position in this world, experimental physiology as a path to knowledge about the human body made sense because human beings were perceived as having sufficient shared characteristics with other animals. This did not, however, mean that scientists rejected providence or a higher soul. When physicians began to speak about ideas and emotion as automated physiological processes this was for many a controversial move. Both within and beyond scientific communities physiologically anchored theories of mind met with objections from Christian writers. Thomas Dixon notes that reactions among Christian thinkers were far 
from unified; nonetheless, a shared point of antagonism between many of them was that the new physiological psychology left little or no room for a higher, abstract soul. ${ }^{6}$ The idea of emotion as a reflexive, automated function was possible within a system of thought that took emotion to be a bodily and often also a cerebral process. ${ }^{7}$ This latter point constituted an important division between physicians who believed in different models of psychological reflexion. The kind of model of involuntary reaction of emotion and ideas in conjunction that formed the basis for biomedical theories of melancholia generally held emotion to be a cerebral activity rather than a reaction occurring in a lower part of the nervous system. The significance of this distinction is illustrated below in the contrast between the psycho-physiological theories offered by Thomas Laycock and William Benjamin Carpenter.

Viewed as a psychological reaction, 'emotion' would in one sense become a broader category than the traditional 'passions', 'sentiments', and 'appetites'. As a secular, psychological category, 'emotion' would gradually replace such older terms anchored in a theistic language and view of the body-mind relationship. At the same time, however, emotion as understood within physiological psychology and psychological medicine was a narrow category, in that it was perceived as a process, or event, contained within the human nervous system. ${ }^{8}$ This way of explaining the mental life of humans did not mesh comfortably with the possibility of an intellect belonging to a higher soul and capable of disciplining the lower animal appetites. However, as Smith has noted, the new scientific discourse about mind and body remained steeped in moral argument. ${ }^{9}$ Indeed, as the century wore on a person's immorality became an increasingly biological feature, permanently imprinted on degenerate brains and bodies. ${ }^{10}$

\section{The Reflex Concept}

The theory of reflexive action was a chief preoccupation of European physiologists early in the century and formed the basis of and rationale for numerous experiments on living animal bodies. Ruth Leys has referred to the reflex concept as espoused by nineteenth-century experimental scientists as 'one of the most influential explanatory principles in the history of the medical, biological, and psychological sciences', noting that 'it has played a major role in the rise of psychology as an experimental science'. ${ }^{11}$ Smith and L.S. Jacyna have both drawn attention to 
the role of the reflex in the development of nineteenth-century British psychopathology. ${ }^{12}$ Building on existing historical work in this vein, the emphasis here is on how the reflex model facilitated the creation of disordered mood as a medical concept, a concept that was foundational to melancholia as a modern biomedical mental disease. This transfer of knowledge from neurology and nervous physiology to psychology and psychiatry was neither inevitable nor straightforward, and, as is demonstrated below and in Chapter 4, a significant amount of intellectual labour was required to bring it about.

A driving force behind physiological research in the nineteenth century was the objective of 'knowing the body', and with it the brain. Roger Cooter has observed that the knowledge produced through such research had little practical use for ordinary people, the way earlier medical selfhelp manuals and recipe books had had. Yet this nascent science held the power to reveal 'what was hitherto a mystery for most people, the internal operations of their bodies. ${ }^{13}$ For scientists who believed that the production of ideas and emotions was the result of cerebral activity, knowing the body also meant knowing the mind. As suggested above, experiments on living animal bodies occurred within a belief system about the natural world without which it would not make sense to conduct such experiments in the first place. In this context, the nervous system was conceptualised and visualised along certain lines, it was discussed in terms of 'reactions', 'reflexes', 'sensation', 'irritation', stimulus', 'tone', and 'motion'.

While 'reflex' came to mean something quite specific in medicoscientific literature in the mid-to-late nineteenth century, the idea of reflexive action as something occurring inside the human body was not the invention of experimental physiologists. Any attempt to trace the origins of the reflex concept beyond the modern period must, however, be carried out with the same kind of historical and contextual sensitivity as is called for when comparing ancient, medieval, and early modern writings on melancholia with nineteenth-century literature. Historians (and nineteenth-century scientists) have offered different views on the history of the modern sensory-motor reflex. The invention of the concept has been attributed to Descartes, ${ }^{14}$ whereas others have highlighted British physician Marshall Hall as one of the key figures in its creation. ${ }^{15}$ Ruth Leys agrees that Hall's theory of the 'reflex arc' was central to modern ideas about involuntary reflexive action, but she cautions historians against perceiving the reflex as having 'developed in a linear or 
incremental fashion towards the present' ${ }^{16}$ Hall's theory of reflexive action was, she suggests, equally a rearticulation of older ideas about 'sympathy'; moreover, it was purely 'mechanistic', almost in a Cartesian sense. For Hall, '[ $t$ ] he central nervous system was subject to the laws of the reflex as high as the medulla but no higher: above the cord was the entirely different cerebral system, the seat of the immortal soul'. ${ }^{17}$ Hall's conception importantly allowed for volition as a faculty independent from and higher than reactions anchored in the body. In this way, it followed along the lines of older, broadly Christian beliefs, which held that the higher faculties were able to exert control over the lower ones (such as 'animal passions'). ${ }^{18}$

Much of the language that came to be used to speak about emotion was metaphorical in its origins. While we may, as historians have done, speak about the reflex having been 'extended' to the realm of ideas and emotion, such a narrative suggests a progressive, indeed an almost teleological, development. Nineteenth-century scientists did not simply follow a path of step-by-step discovery. The acts and events that create scientific objects are never simple and uncontested, and the creation of psychological reflexion, and of disordered emotion, was a particularly imaginative endeavour. A new generation of scientists was keen to use novel empirical research to try to make sense of that which had perplexed and mystified European philosophers since antiquity-what is it that makes humans think, feel, act, and react? An area of inquiry that used to belong chiefly to philosophy was increasingly being staked out by medical scientists through the appropriation of medical language from the realm of the physical to that of the psychological. Concepts that have solid and naturalised meanings in psychology and psychiatry today began their journey as metaphors borrowed from internal medicine.

\section{IRritation AND MORBID SENSIBILITY: From Internal to Psychological Medicine}

As British writers themselves noted, most of the cutting-edge research in the area of experimental physiology was being carried out on the continent. However, home-grown publications were not entirely absent, and a handful of early Victorian authorities on the subject were emerging in the 1830s and 40s. Charles Bell and Marshall Hall were both important champions of neurophysiological theories on the continent as well as in Britain, and their work has been considered in detail by historians. 
However, other less prominent writers also had a significant impact on the development of physiological psychology in Britain, and an even greater influence on the emerging concept of disordered mood. Of particular significance in this regard was Archibald Billing's popular First Principles of Medicine, published in several editions between the 1830s and the 1860s and widely consulted and cited by British physicians with an interest in the brain and the mind. Billing, physician, lecturer and clinical instructor at the London Hospital in Whitechapel, ${ }^{19}$ eagerly emphasised his own role in the establishment of physiological ideas about cerebral activity, alongside some of his more famous peers. ${ }^{20}$

Billing's textbook underwent several revisions, but his approach to nervous action was strictly somatic from the outset. He suggested that all nervous function was best understood as analogous to electricity, and held that this may be more than an analogy, since the application of an electric current to the nerves would prompt muscle contraction (something which scientists had noted since the seventeenth century). Billing situated his treatise within the framework of experimental physiology, drawing indirectly upon experiments performed on living animals, particularly frogs, where surgically exposed nerves were subjected to electric currents intended to produce reflexive movement. In a presentation of different ways in which various bodily reactions simulated electricity, Billing also suggested as an example "[v]olition being conducted along the nerves with a speed equal only to electricity'. ${ }^{21}$ In this way, the will was conceptualised as a physiological process; no distinction was made between involuntary reaction as somatic and voluntary action as mental.

Two things are important to note about Billing's work. First of all, his physiological model was a fusion of old and new language and concepts. Billing's illustration of nerve force bore evident resemblance to eighteenth-century natural philosophy, and ideas about 'irritation' as a trigger of nervous function looks superficially similar to von Haller's concept of 'irritability' put forward in the 1750s and which explained involuntary muscular reaction in response to stimuli. For Haller, however, 'the power of contraction resided in the muscle itself' and was the result of a 'nerve force' or vis nervosa. ${ }^{22}$ This illustrates the argument made above, that while much early modern terminology was slow to disappear, similarity in language should not be mistaken for conceptual sameness. Secondly, we should not take his statement above to mean that Billing perceived volition as a reflexive act. He circumvented the problem of an 
independent will in a biological framework by suggesting that sensation, action, and reaction in the human body were carried along two different sets of nerves-voluntary and involuntary. ${ }^{23}$ Despite this attempt to keep the will intact, we can note the possible consequences of Billing's argument. He made it clear to his readers that '[a]ll organic action is contraction, produced by nervous influence'. ${ }^{24}$ This would appear to suggest that Billing held all mental activity to be a manifestation of such contraction; however, his somatic model of nervous activity did not extend to intellectual life. In other words, while volition was transmitted along nerve paths, it was not an automated somatic reaction. Not only did Billing perceive a separation between bodily activity and the mental faculties; the detailed study of 'the properties and processes' of the human body was ultimately a revelation of 'the omniscience of the Deity'. The body was, in the end, merely a 'structure' that 'the Soul' was 'destined to inhabit for but a short space of time'. ${ }^{25}$

In First Principles of Medicine we find a number of medical concepts that would become foundational to physiological theories of mental disease. Two of these are particularly important for our present enquiry: 'irritation' and 'morbid sensibility'. Billing used the latter to describe 'that state of the nerves or central organs which renders them more susceptible to impressions than natural'. ${ }^{26}$ Billing explained the occurrence of such sensibility in different organs through the application of 'the reflex theory'. The inherent sensibility of nerves would render these susceptible to 'irritation', which in turn could produce morbid sensibility:

If, therefore, certain diseased states, unaccompanied by pain, termed 'irritation' (which term can properly be applied only to whatever is the cause of the morbid sensibility), exist in a part of which the spinal cord takes cognizance, and which are indicated by subsequent production of abnormal muscular contractions, \&c. in distant parts of the body, it follows that the spinal cord has become sensible of that diseased state, that is, has participated in the morbid sensibility, although the brain has not been informed of it. ${ }^{27}$

The idea of 'irritation' of the nerves causing an organ to become morbidly sensitive would become central to the kind of physiological explanation for disordered emotion offered by later writers. As will be seen below, it is important to note that Billing perceived this process as happening without cerebral involvement. By this he not only meant that the mind was not 
aware of it, but also that it was a reactive process that did not reach the brain hemispheres. In this way, Billing was consistent with standard medical opinion at the time in that he did not deviate from the distinction made by Hall and others between voluntary and involuntary action where the latter was somatic and the former cerebral or even outside of the body completely. In other words, involuntary action could only occur without cerebral involvement, as a reaction triggered below the brain, no further up than the medulla. It was a separation that was physical in its description, but of which the consequences were also psychological. However, as shall be seen in a moment, when scientists extrapolated such concepts to speak about ideas and emotion, a framework was created whereby involuntary reaction could occur in the brain but still without conscious awareness.

Billing went on to describe precisely how disease would arise from the state of irritation, suggesting that "[i]f the nerves of sensation be rendered morbidly sensitive, pain is produced by common occurrences which ought not to affect them, such as pressure either from external things, or even of the surrounding parts'. ${ }^{28}$ This metaphor would above all become key to explaining biomedical melancholia; indeed one may go so far as to say that it formed the rationale for melancholia as a disorder. The idea of how a morbid reaction to normal impressions could occur would become part of standard descriptions of melancholia as a disease in which ordinary impressions that would trigger no emotional reaction in a healthy mind would produce 'mental pain' and 'depression'. ${ }^{29}$ Similar models were offered by other contemporaneous British writers who, like Billing, referred much of the current knowledge on the anatomy and physiology of the nerves to Bell and Magendie. A work that received particular interest among mid-century medical psychologists was Samuel Solly's The Human Brain, first published in 1836 with an updated second edition a decade later. Solly's book was to a large extent an account and discussion of recent French research. The first edition was also chiefly concerned with the anatomy and physiology of animal brains-i.e. data directly derived from empirical research-with some extrapolations regarding the human brain. ${ }^{30}$ Overall, two recurrent themes in particular should be noted in regard to British medico-scientific literature on the physiology of the nervous system prior to the 1840s: the idea that persistent 'irritation' of the nerves caused them to become more sensitive and prone to morbidity, and, a model of involuntary reflexive action that did not include the cerebral hemispheres in such activity. 


\section{From Sensory-Motor Reflex to Psychological Automatism}

While Billing and Solly's frameworks were later taken up in and adapted to psychological medicine by the next generation of British physicians, in the early decades of British mental science the impact of work produced by continental writers was at least as substantial, if not more so. Prussian physiologist Johannes Müller's Elements of Physiology ${ }^{31}$ navigated territory that Billing and many other contemporary physiologists had not ventured into. Müller was curious about the psychological implications of physiological research and attempted to draw parallels between the human psyche and sensory-motor experiments performed on animals. His work contains the beginnings of the kind of analogous transfer of concepts that would form the core of later theories about affective insanity. Müller's Elements provided mid-century physicians with tools allowing them to hypothesise about psychological (and thus emotional) reflexive action.

Müller, who trained rising stars such as Hermann von Helmholtz and Emil du Bois-Reymond, was appointed to the first German chair of physiology in $1833,{ }^{32}$ the same year as the first volume of his Elements of Physiology was published. This work drew upon experiments performed by Müller himself as well as data derived from other people's research, and a substantial chunk of the book was devoted to the workings of the nervous system, including the brain and the mind. For many early nineteenthcentury German scientists, their convictions about the place of human beings as part of the animal kingdom and natural world were rooted in Naturphilosophie, generally regarded as belonging to Romanticism and, from a scientific point of view, somewhat pre-modern. However, as Jutta Schickore has suggested, these beliefs had much in common with later, post-Darwinian explanatory frameworks. In particular, the unity of 'Man' and nature is important in this regard, and philosophical ideas within this early tradition had an impact on scientific endeavours later on. ${ }^{33}$ One of the most influential explanations of human ability to acquire knowledge about nature arising from Naturphilosophie came from Friedrich Schelling, who argued that 'we are able to have knowledge about the natural world because nature and the human subject are essentially the same'. ${ }^{34}$ Müller came out of this tradition, but largely rejected Schelling's views. His own beliefs were complex, however, not least because he was a prolific researcher who carried out work within a vast number of different areas of physiology. Nevertheless, Schickore suggests that he was in the 
first instance concerned with 'the overall problem of how living things could be experienced' ${ }^{35}$ This perspective was important for how a new generation of scientists in the German-speaking areas approached their work. While for many laboratory scientists empirical research continued to be carried out within a loose framework of older philosophical and spiritual beliefs about the world, 'a new accent on academic, original research came together with an explicit preference for experience over speculation'. ${ }^{36}$

For Müller, emotion was a manifestation of nervous action; a physiological process of the interconnected brain-body system. Perhaps seeking to distance himself from the populist science of phrenology, he remarked that ' $\mathrm{t}]$ here are no data for either proving or refuting the hypothesis that the passions have their seat of action in a particular part of the brain'. He went on to emphasise the ability of emotion to trigger peripheral bodily reactions:

The exciting passions give rise to spasms, and frequently even to convulsive motions affecting the muscles supplied by the respiratory and facial nerves. Not only are the features distorted, but the actions of the respiratory muscles are so changed as to produce the movements of crying, sighing, and sobbing. Any passion of whatever nature, if of sufficient intensity, may give rise to crying and sobbing. Weeping may be produced by joy, pain, anger, or rage. ${ }^{37}$

What Müller described, then, was how emotion could excite involuntary movement elsewhere in the body. Andrew Hodgkiss has suggested that Müller also envisaged reflexive action as a potentially psychological activity. $^{38}$ The German physiologist did indeed allow for the mind to be excited by external stimuli. This was how he perceived ideas to arise, stating that 'an idea or conception is that which is excited in the mind by impressions on the senses, or by those actions of our own body which are communicated to the sensorium'. ${ }^{39}$ According to this model, ideas could react upon stimuli originating from outside the body, or from other parts of it. This model was taken up and developed by Thomas Laycock in Britain and Wilhelm Griesinger in Germany, who would suggest that ideas and emotions were not only triggered by external stimuli, but also by activity elsewhere in the body. As will be seen in Chapter 4, Griesinger abstracted from this model an analogous process whereby ideas and emotions would react upon one another, producing novel mental states. 
If the brain was subjected to repeated external and/or internal 'irritation', the process of intra-cerebral reflex action would result in persistent mental pain-the manifestation of pathological mood.

\section{The Physiology of Disordered Emotion in Mid-Century British Medicine}

Kurt Danziger has referred to British physician Thomas Laycock as 'one of the most original minds' among his contemporaries. ${ }^{40}$ Laycock left his home county of North Yorkshire to begin his medical studies at University College London in 1833, where he became acquainted with William Benjamin Carpenter when they both attended Robert Grant's optional classes in comparative anatomy. ${ }^{41}$ Tom Quick suggests that Grant's lectures helped shape the future research interests of both students, and quotes Laycock as later remarking that "Carpenter "set on the same researches with himself when both were studying comparative anatomy and physiology". ${ }^{42}$ Having graduated as a Member of the Royal College of Surgeons in 1835, Laycock obtained a position at the York County Hospital the following year. During his time on the female wards at York he published a series of papers on hysteria, out of which emerged his first monograph. A Treatise on the Nervous Diseases of Women ${ }^{43}$ appeared in 1840, shortly after Laycock received a doctorate in medicine from the University of Göttingen. He was later appointed to the chair in medicine at Edinburgh University, where he would also go on to lecture on metal diseases, remaining there until his death in $1876 .{ }^{44}$

In the 1870s, Laycock and Carpenter would become engaged in a dispute over who had first articulated the idea of psychological involuntary reflexion, or 'unconscious cerebration' as some mid-century British writers called it. The invention of the term 'unconscious cerebration' has been attributed to Carpenter, ${ }^{45}$ and he appears to have used it first in the 1842 edition of his Principles of Human Physiology. Laycock claimed to have suggested the idea of unconscious cerebral reflexion before Carpenter, first in On the Nervous Diseases of Women in 1840, and in a separate article a few years later. ${ }^{46}$ The sometimes antagonistic relationship between the two physicians has been engagingly portrayed elsewhere ${ }^{47}$; its bearing upon the present story centres on what unconscious cerebration or involuntary psychological reflexion was meant to convey, how this concept related to Carpenter's term 'ideo-motor' reaction, 
and what the significance of these models was for mid-Victorian theories of disordered mood.

\section{William Benjamin Carpenter}

Carpenter developed an impressively substantial framework for physiological psychology in the multiple editions of his widely read Principles of Human Physiology, first published in 1842. His theory of mind embraced certain metaphysical principles that set it apart from those offered by Laycock and Griesinger. Carpenter developed a hierarchical table of the nervous system, which also included a division of mental functions. At the lowest level he situated 'the true spinal cord', followed by the medulla oblongata. The next level up was 'the ganglia of the nerves of special sensation', and finally 'the cerebral hemispheres', the latter being the seat of the will. ${ }^{48} \mathrm{He}$ perceived reflexive action to occur not only in the medulla, but also in 'the ganglia of the nerves of special sensation'. Importantly, involuntary reaction occurring in this higher sphere could be distinguished from the former as it would be 'attended with consciousness, and also, it would appear, with certain peculiar feelings' 49 This, then, was the seat of emotion (together with the five senses), which for Carpenter had distinctly somatic and animalistic qualities not dissimilar from more traditional conceptions of animal passions and appetites. Volition and emotion belonged to separate spheres in Carpenter's model, and only the latter was prone to the kind of automatism that facilitated physiological theories of insanity. As will be seen below, this was a significant factor setting his framework apart from that developed by Laycock.

According to Carpenter, reactions occurring in the second highest part of the nervous system were 'commonly termed instinctive in the lower animals, and consensual and emotional in ourselves; these all correspond, in being performed without any idea of a purpose, and without any direction of the will, - being frequently in opposition to it'. The result was that in Carpenter's model emotion was a reflexive activity that could occur in conflict with the will. In other words, emotion was something the control of which was at once difficult and desirable, but most importantly possible. For volition belonged to a separate, higher sphere, that of the cerebral ganglia, and as such was 'capable of acting in greater or lesser degree, on all the muscles forming part of the system of Animal life' ${ }^{50}$ That is, while Carpenter allowed for psychological reflex action, he perceived it as applicable to 'emotions' and 'instincts', and in later editions of his book 
to some extent also to 'ideas', but when it came to the will he would not concede to its reduction to a physiological process. In a turn of phrase that brings Hall's dualism to mind, Carpenter suggested that while psychology shared on the whole the same principles as physiology, it was wrong to conceive of 'the Thinking Man' as a 'puppet that moves according as its strings are pulled'. Rather,

he also possesses a self-determining power, which can rise above all the promptings of external suggestion, and can, to a certain extent, mould external circumstances to its own requirements, instead of being completely subjugated by them. We can scarcely desire a better proof that our possession of this power is a reality and not a self-delusion, than that which is afforded by the comparison of the normal condition of the mind, with that in which the directing power of the Will is in abeyance. ${ }^{51}$

It follows from this that a healthy mind would be able to exercise volition to control the other faculties, but in conditions of abnormality, i.e. mental disease, the ability of the individual to direct their will could be compromised. That is, Carpenter insisted on keeping the will separate from and superior to emotion, but he nevertheless allowed for the possibility of the former becoming compromised by the latter. Carpenter abandoned his tabular division of the nervous system in later editions of his textbook; however, he maintained the separation of the will from the emotions, concluding that, '[t] hat the Emotional and Volitional movements differ as to their primal sources, is obvious'. ${ }^{2}$ He thus stayed committed to a clear separation of the will from emotion throughout his career. ${ }^{53}$ In this way, Carpenter's theory of mind set itself apart from the more strictly biomedical approach of Laycock, as well as that of a new generation of asylum physicians, such as Henry Maudsley, who would apply physiological language to theories of mental disease. ${ }^{54}$

In the 1855 edition of Principles, Carpenter attempted to explain the relationship between mind and body through 'a correlation of forces'. There could be no analogy drawn between 'mind' and 'matter'; such a theory was ultimately flawed. However, with the nervous system operating through nervous force, the will could be conceived of as a mental force. In this way, 'nerve-force' could be excited by 'mental agency' and vice versa. This 'correlation of forces' could, he argued, explain the relationship between 'emotional excitement and bodily change', as well as the emergence of ideas in the mind and the subsequent 'action of those 
ideas upon the centres of movement'. ${ }^{55}$ Carpenter assigned this latter operation to the brain itself, giving it the term 'ideo-motor' action. This kind of action was, importantly, both conscious and involving the will in its execution. In this way, Carpenter's model was qualitatively different from the theory of cerebral reflexion developed by his former university associate Thomas Laycock.

\section{ThOMAS LAYCOCK}

In seeking to explain the 'convulsions', 'fits', and 'paroxysms' of his female patients at York, Laycock drew upon recent research into the physiology of animal bodies with which he had become acquainted during his studies. ${ }^{56}$ In On the Nervous Diseases of Women (1840), he suggested that most cases of hysteria had an emotional basis, and that the female reproductive system played a central role in producing hysterical fits. Internal, organic actions could, Laycock suggested, trigger a reaction in the brain. Women were particularly prone to such excitability, since their reproductive organs were disposed to causing internal tension and imbalance, upsetting an already weaker and more susceptible constitution. In other words, women were more likely to experience involuntary emotional reactions triggered by external or internal stimuli. Thus, the women's wards at York offered Laycock an optimal stage upon which to observe reflexive emotionality in action. Jacyna observes that '[h]e saw an analogy between [epilepsy] and the "emotional" convulsions of hysteria. It was to explain this analogy that Laycock argued for an extension of the reflex model of nervous action from the spine to the encephalon'. ${ }^{57}$

In On the Nervous Diseases of Women, Laycock offered the following description of reflex action:

We find that changes excited in the system by the action of external forces are communicated to the brain by the sensitive nerves; that will act upon the muscles so as to excite motion trough the motor nerves, and that a third class of nerves, the organic, ${ }^{58}$ are subservient to the perfection, preservation, and repair of the vital mechanism, and are influenced by certain mental agencies of which we are conscious, - as the emotions, - but which are independent of the will. ${ }^{59}$ 
Through the class of 'organic' nerves, then, Laycock was able to suggest that cyclical and reproductive changes playing out within the female body could excite the brain and trigger reactions in the form of a range of hysterical-emotional convulsions. However, as we can see, the emotions were correspondingly able to influence bodily functions, independent of volitional control. It was relatively easy for Laycock to proceed from this discussion to drawing a tentative analogy between motor and 'sensorial'60 reflexion:

The analogy between the voluntary and involuntary systems of motor and sensitive nerves is partly demonstrated by the previous facts; it remains to inquire whether there be anything in the changes produced in the sensorial system by external and internal stimuli analogous to those excited in the motor. Of these changes it is certain we can only judge by the phenomena produced in each case, sensation being analogous to movements, abolition of consciousness to motor paralysis. ${ }^{61}$

This kind of analogy would become central to physiological theories of mental disease. The biomedical language on emotion was riddled with metaphors and analogous explanatory models; as will be seen in subsequent chapters, this language would underpin symptoms of melancholia, such as the ubiquitous 'mental pain' (or psychalgia-a term sometimes used to emphasise its analogous relationship to neuralgia ${ }^{62}$ ). While Laycock displayed some caution in comparing motor and mental reactions, he had little doubt that the brain as an organ was involved in reflexive action, as the 'nervous connexions' running to and from the periphery in his view clearly extended to the cerebral hemispheres. Moreover, he was not blind to the potentially revolutionary implications of such a theory. 'How vast', he exclaimed, 'is the field of inquiry opened out by an application of the laws of reflex function to these structures!'63 And vast it was indeed. The idea of emotion and even ideas as potentially reflexive, automated, and subject to disorder, has proved one of the most durable legacies of nineteenth-century psychological medicine.

Laycock continued to develop his 'field of inquiry' in his 1844 paper 'On the Reflex Function of the Brain', cited at the start of this chapter. The aim of the paper, he stated, was to 'prove' his earlier claims about cerebral reflexion. Using the example of 'hydrophobia' (fear of water), 
Laycock outlined three ways in which such phobia could be induced'three classes of irritations [of the brain] inducing the reflex acts of gasping and spasm of the respiratory muscles'. The first two involved either the sight of water or bodily contact with it. The third referred to 'an idea excited by the sound of water dropping, or by the mention of water'. ${ }^{64}$ Once the fear of water-an emotional reaction-had been induced, the patient 'immediately attempts to remove it. This movement is strictly involuntary, and not the result of sensation'. ${ }^{65}$ What the reader was presented with, then, was a process whereby a morbid emotional reaction producing involuntary muscular movement could be triggered by an idea alone, rather than by sensory stimuli to the body. Laycock did not name this process, but it is similar to what Carpenter termed 'ideo-motor' activity, to distinguish it from sensory-motor action. What Laycock did was to describe the means by which this kind of ideationally induced morbid reaction could occur, again by using the analogy of involuntary or automatic sensory-motor action:

[S]ince an infinity of muscular acts are already inscribed within the structure of the anterior gray matter of the spinal ganglia, and require only the appropriate sensory impression to rouse them into action, so ideas may be inscribed and require only sensory impressions to rouse them. ${ }^{66}$

Danziger notes that Laycock was able to use these principles to explain 'hitherto puzzling phenomena such as somnambulism, hysteria, impulsive insanity, and bizarre religious behaviour. ${ }^{67}$ Laycock described, for instance, a case of a young girl who began to develop rhythmical spasmodic muscular movements, which over several days developed into 'a graceful dance' conducted to the melody of the song 'Protestant Boys', which the patient claimed to be constantly 'dwelling upon her mind'. When the music became more 'pressing', this 'impelled her to commence the involuntary actions'. Laycock explained this phenomenon as caused by 'centric changes, which had induced this alteration of sensory function, and which had reproduced in fact the idea of the air with such force that it impinged upon the motor track, and there excited consentaneous reflex acts, in spite of the utmost volitional effort of the individual'. ${ }^{68}$ As will be seen in Chapter 4, the notion of ideas being inscribed onto the brain, to be aroused anew at any moment by application of appropriate stimuli, was developed in more detail by Griesinger, who offered 
the idiom 'mental storages' for the space where ideas were collected in the brain.

While Laycock and Carpenter were no doubt two of the most influential writers of their generation, similar theories were offered by other British medical scientists in the 1840s and 50s. For instance, William Senhouse, physician and anatomy teacher at St. Bartholomew's in London, offered a model of nervous function adopting a stricter level of materialism than Carpenter while still being less radical than Laycock. Senhouse followed Carpenter in separating the 'sensory ganglia' from the 'cerebral hemispheres', with the former being subject to involuntary reaction. The brain itself Senhouse described as the seat of attention, volition, perception, memory, imagination, and judgement, faculties which were all independent of the lower animal functions. ${ }^{69}$ However, the operation of these cerebral faculties could still potentially be compromised, resulting in morbidity:

In health, the mind combines the impressions received by the two hemispheres, and produces from them single ideas, like as in healthy vision the impressions on the two retinæ give rise to a single perception. In certain forms of disease, however, in which, perhaps, one or both hemispheres are disordered, the same object may produce two separate sensations, and suggest simultaneously different ideas; or, at the same time, two trains of thought may be carried on, by the one mind acting, or being acted upon differently in the two hemispheres. ${ }^{70}$

As will be seen in Chapter 4, this ability of the brain to produce unwanted ideas was a key element in German psychiatrist Wilhelm Griesinger's model of psychological reflex action. Unlike Senhouse, who paid scant attention to emotion, for Griesinger the emergence of morbid ideas was closely related to morbid emotionality and the development of melancholia.

\section{Morbid Sensibility and Morbid Introspection}

In the second half of the nineteenth century, models of involuntary psychological reaction and the metaphorical language used to create such models would facilitate a reconceptualisation of melancholia into a modern biomedical disease of disordered emotion. More broadly, psychological reflexion and physiological psychology offered Victorian asylum 
physicians a range of useful tools with which to explain the maladies of their patients. In $O n$ the Nature and Proximate Cause of Insanity (1853) James Davey drew upon Billing's model of mental physiology to suggest that in people suffering from mental disease, the 'nervous power' was easily "converted into "irritation" or "morbid sensibility", and this fact is well illustrated by the origin and progress of almost any case of mental derangement'. ${ }^{71}$ This argument was further developed in a series of 'Lectures on Insanity' published in the Association Medical Journal in 1855, where Billing's concepts 'morbid sensibility' and 'irritation' were presented as central to the emergence of mental disease, and theories within a metaphorical image of muscle contraction:

Long continued mental exertion, protracted anxiety, or excessive action of any one or more of the cerebral faculties, lead, ere long, to a morbid sensibility of a portion or portions of the cineritious neurine ${ }^{72}$; this, the source of power, intellectual and emotional, if overtasked, loses, like any ordinary muscle, the capacity to respond duly to the too frequent and long continued calls made on it; and it assumes, therefore, a condition of irritation (excitement without power) which, if allowed to proceed unchecked, or if not relieved, realises all the external indications of mental derangement. $^{73}$

The idea of morbid sensitivity of the brain and the mind equally found an abstract application as a means of explaining an old philosophical idea about the causal relationship between solitary introspection and a melancholy state of mind (potentially leading to melancholy madness). Michael Clark has suggested that Victorian medical psychologists held up 'morbid introspection' as an important factor in the aetiology of mental disease. ${ }^{74}$ In Clark's narrative of Victorian psychological medicine, morbid introspection was the factor often seen to distinguish an 'unsound Mind' from 'mental soundness'. Defined as 'the habitual turning of the mind inwards upon itself to the virtual exclusion of external impressions, accompanied by the temporary or partial suspension of will or judgment,, 75 physicians agreed that morbid introspection fed an unhealthy imagination, leading certain ideas to become dominant and thus destructive to mental health. In this way, emotionality and obsessive ideas would take over at the expense of volition and rational thinking. ${ }^{76}$ Clark's narrative is premised upon a view of insanity where 'the condition of "sound Mind", in which reason and will governed the succession of thought 
and feeling, was familiarly contrasted with that of "unsound Mind", in which reason and will were at least temporarily in abeyance, and emotion, nourished by imagination, held unchecked sway'. ${ }^{77}$ However, within the physiological framework for mental activity embraced by mid-tolate nineteenth-century physicians, such a division could not be so easily made. Emotion and volition were not necessarily seen as separate. This was particularly evident in melancholia, and will be considered further in subsequent chapters. A number of physicians would describe melancholics, especially in the early or non-delusional stages of the disease, as being fully capable of reasoning about their morbid emotionality yet unable to think themselves out of their despair. Indeed, this tension was, so the argument went, what drove many melancholics to commit suicide, as this appeared the only 'logical' solution to their suffering. ${ }^{78}$ The adoption of physiological language by physicians writing on mental disease led, if anything, to an increasingly complex view of the human mind, one in which the boundary between normal and pathological was perpetually fluid and contested.

By the 1850s, physiological theories of affective insanity were gaining ground among British alienists. Such explanatory models would become increasingly useful later in the century as a biological, evolutionary view of human nature, and of health and illness, gained wide acceptance within the medico-scientific world, and increasingly also outside it. The internal disease model offered by physiological psychology meant that melancholia could be plausibly explained as a biomedical condition in the apparent absence of structural changes to brain tissue. In other words, within a biological system of knowledge, the lack of visible evidence in the form of lesions did not have to preclude the presence of mental disease. As one British physician put it, 'insanity really is a disease of the brain', and an adherence to a physiological view of the mind must lead physicians to recognise that

the absence of post mortem evidence, even when it is satisfactorily proved to exist, is no argument against the correctness of this opinion, because such a result may merely arise from the real changes being too minute to be detected by the processes in ordinary use for anatomical investigation. ${ }^{79}$

Thus, the stage was set for a new generation of medical psychologists who were increasingly concerned with diagnosis and classification of mental disease and who sought to anchor their nascent discipline firmly in the conceptual realm of medical science. 


\section{Conclusion}

This chapter has shown how concepts borrowed from experimental physiology and internal medicine were used to speak about the psychology of emotions in biological language. Terms like 'irritation' used to describe the state and function of organs were applied to the mind within a framework where mental activity was conceptualised as the unseen but presumed activity of the brain. Laycock explained mental operations through the concept of cerebral reflexion and perceived the emotions, together with ideas and the will, as produced in the brain-such reflexive action was, in other words, both psychological and cerebral. Carpenter, however, maintained that the emotions were separate from a higher intellect, which retained some measure of control of the former. This tension between emotion and volition would continue to inform discussions about disordered emotion, and melancholia, and were at the heart of ideas about mental pathology embraced by late-Victorian asylum physicians, many of whom drew on Laycock and Carpenter, as well as on the work of influential psychiatrist Wilhelm Griesinger, whose theories of psychological reflex action and the aetiology of melancholia are discussed in Chapter 4.

Physiological psychology came to inform medico-scientific conceptions of the mind and its disorders in the Victorian period, allowing for melancholia to gradually become reconstituted as 'disordered emotion' and as such a modern biomedical mental disease. The consequences of this event were significant for how insanity was perceived in nineteenth-century medicine, not least as it increasingly blurred and shifted the boundary between healthy and pathological emotions. As will be seen in Chapter 5, towards the end of the century physicians were increasingly concerned with 'simple' or non-delusional melancholia. This did not merely manifest in an expansion of the sphere of emotional disorders, but also, and perhaps in a sense conversely, it facilitated the argument that emotional states which physicians themselves considered to be non-pathological could nonetheless legitimately fall within the purview of psychological medicine. Moreover, the development of a physiological model for mental disease did not only have consequences for conceptions of insanity in the nineteenth century. The model of disordered mood that emerged mid-century has proved durable in modern psychiatry, psychology, and neuroscience. It continues to guide present research into the emotions and their disorders, but more than this, it importantly governs what we 
perceive emotion to be, both as a central aspect of the human condition, and as a private and intimate experience.

\section{Notes}

1. J. Hawkes, "The Materialism of Insanity," Journal of Psychological Medicine and Mental Pathology 8 (1855): 313.

2. Thomas Laycock, "On the Reflex Function of the Brain," British and Foreign Medical Review 19 (1845): 303.

3. See e.g. David Cahan, ed., From Natural Philosophy to the Sciences: Writing the History of Nineteenth-Century Science (Chicago: University of Chicago Press, 2003); Peter J. Bowler, Evolution: The History of an Idea (Berkeley: University of California Press, 1989); Timothy Lenoir, Instituting Science: The Cultural Production of Scientific Disciplines (Stanford: Stanford University Press, 1997); Lorraine Daston and Peter Galison, Objectivity (New York, Zone Books, 2007).

4. Roger Smith, Inbibition: History and Meaning in the Sciences of Mind and Brain (London: Free Association Books, 1992), 15.

5. Smith, Inhibition, 15. See also Frank Turner, "The Victorian Conflict between Science and Religion," Isis 69 (1978): 356-376.

6. Thomas Dixon, From Passions to Emotions: The Creation of a Secular Psychological Category (Cambridge: Cambridge University Press, 2003), 180-203.

7. Fay Bound Alberti has traced the shift from ideas about the heart as the seat of the passions and the soul to the modern perception of the brain as the organ of the mind. As Alberti suggests, despite the pervasiveness of neurological discourses on human emotionality in the modern period, the heart remains as a remarkably durable cultural symbol for feeling, particularly love and affection. Fay Bound Alberti, Matters of the Heart: History, Medicine, and Emotion (Oxford: Oxford University Press, 2010).

8. Dixon, From Passions to Emotions; Roger Smith, "The History of Psychological Categories," Studies in History and Philosophy of Biological and Biomedical Sciences 36 (2004): 55-95.

9. Smith, Inhibition, 11-16.

10. Historical literature on degeneration abounds. See e.g. Daniel Pick, Faces of Degeneration: A European Disorder, c. 1848-1918 (Cambridge: Cambridge University Press, 1989).

11. Ruth Leys, From Sympathy to Reflex: Marshall Hall and His Opponents (New York: Garland Pub., 1990), 1.

12. Smith, Inbibition, 42-55; Jacyna, "Somatic Theories of Mind," 235240. David Healy also notes the importance of neurophysiology and the reflex concept for the development of modern psychopathology. David 
Healy, The Antidepressant Era (Cambridge, MA: Harvard University Press, 1997), 31.

13. Roger Cooter, "The Power of the Body," in Natural Order: Historical Studies of Scientific Culture, eds. Barry Barnes and Steven Shapin (London: Sage Publications, 1979), 75.

14. Canguilhem suggests, however, that to make Descartes the founder of the modern reflex concept is to distort what is understood by reflexive action, since the concept of reflex consists of more than just a rudimentary mechanical explanation of muscular movement. It also contains the idea that some kind of stimulus stemming from the periphery of the organism is transmitted to the centre and then reflected back to the periphery. What distinguishes reflex motion is the fact that it does not proceed directly from a centre or central repository of immaterial power of any kind. Therein lies, within the genus "movement", the specific difference between involuntary and voluntary.' George Canguilhem, "The Concept of Reflex," in The Vital Rationalist: Selected Writings from Georges Canguilhem (New York: Zone Books, 1994), 182-183.

15. Edwin Clarke and L.S Jacyna, Nineteenth-Century Origins of Neuroscientific Concepts (Berkeley: University of California Press, 1987); Leys, From Sympathy to Reflex. Clarke and Jacyna trace the modern concept back to physicians Robert Whytt and Jiř́ Procháska in the eighteenth century, and locate the first tentative ideas about reflexion in Ancient Greece. However, they also suggest that 'Hall's work constituted a landmark in the history of the reflex concept' (p. 105).

16. Leys, From Sympathy to Reflex, 5.

17. Leys, From Sympathy to Reflex, 17-18.

18. For older theistic perceptions of the separation of faculties into a higher and a lower sphere, see Dixon, From Passions to Emotions, esp. pp. 26-61.

19. J. F. Payne, "Billing, Archibald (1791-1881)," in Oxford Dictionary of National Biography (Oxford: Oxford University Press, 2011), http:// www.oxforddnb.com/view/article/2387 (last accessed 6/2/2019).

20. Archibald Billing, First Principles of Medicine, 3rd ed. (London: S. Highley, 1838), preface.

21. Billing, First Principles, 17.

22. Clarke and Jacyna, Neuroscientific Concepts, 103-104.

23. Billing drew inspiration for this model of voluntary and involuntary nerves from turn-of-the-century French physician Bichât. However, Billing found Bichât's distinction between 'animal' and 'organic' sensibility and contractibility unhelpful, as all nervous function was, he argued, 'organic', but carried along either voluntary or involuntary nerves. Billing, First Principles, 17-19.

24. Billing, First Principles, 18.

25. Billing, First Principles, 20. 
26. Billing, First Principles, 108.

27. Billing, First Principles, 109. Emphasis in original. Billing's idea of morbid sensibility should not be conceived of in a strictly modern biological sense; rather, his work must be read against the backdrop of eighteenthcentury ideas about 'nervous sensibility', which in turn carry with them older Newtonian conceptions of the body. Billing's work was, like much early- to mid-nineteenth-century medical theory, illustrative of a shift from natural philosophy to modern science that was gradual, patchy (and often idiosyncratic), and where old and new ideas were fused in a number of different ways. For 'sensibility' in eighteenth-century medical writings, see e.g. Anne C. Vila, Enlightenment and Pathology: Sensibility in the Literature and Medicine of Eighteenth-Century France (Baltimore: The Johns Hopkins University Press, 1998); George S. Rousseau, "Nerves, Spirits and Fibres: Towards an Anthropology of Sensibility," in Perilous Enlightenment: Pre- and Post-Modern Discourses, Vol. I: Anthropological, ed. George S. Rousseau (Manchester: Manchester University Press, 1991), 122-141.

28. Billing, First Principles, 109. Emphasis in original.

29. See Chapters 4 and 5.

30. Samuel Solly, The Human Brain, Its Configuration, Structure, Development, and Physiology (London: Longman, 1836). See also Herbert Mayo, Outlines of Human Physiology (London: Burgess and Hill, 1833).

31. Johannes Müller, Elements of Physiology: Vol. II, trans. William Baly (London: Taylor and Walton, 1840 [1837]).

32. Robert M. Young, Mind, Brain, and Adaptation in the Nineteenth Century: Cerebral Localization and Its Biological Context from Gall to Ferrier (New York: Oxford University Press, 1990), 88; Jutta Schickore, The Microscope and the Eye (Chicago: University of Chicago Press, 2007), 134.

33. Schickore, The Microscope and the Eye. For Naturphilosophie at the turn of the century, see Robert J. Richards, The Romantic Conception of Life: Science and Philosophy in the Age of Goethe (Chicago: University of Chicago Press, 2002).

34. Schickore, The Microscope and the Eye, 135. Emphasis in original.

35. Schickore, The Microscope and the Eye, 141.

36. Schickore, The Microscope and the Eye, 134. For a discussion of Müller's role in the development of an emergent modern brain science, see Young, Mind, Brain and Adaptation, 88-92.

37. Müller, Elements of Physiology, 933.

38. Andrew Hodgkiss, From Lesion to Metaphor: Chronic Pain in British, French and German Medical Writings, 1800-1914 (Amsterdam: Rodopi, 2000), 90-91.

39. Müller, Elements of Physiology, 1354. 
40. Danziger, "Psycho-Physiology," 122.

41. Frederick E. James, "The Life and Work of Thomas Laycock, 1812-1876" (PhD diss., University College London, 1995), 22-24; Tom Quick, "Techniques of Life: Zoology, Psychology and Technical Subjectivity (c. 1820-1890)" (PhD diss., University of London, 2011), 91.

42. Quoted in Quick, "Techniques of Life," 91.

43. Thomas Laycock, A Treatise on the Nervous Diseases of Women; Comprising an Inquiry into the Nature, Causes, and Treatment of Spinal and Hysterical Disorders (London: Longman, 1840).

44. author unknown) "Thomas Laycock: Obituary," BMJ September 30 (1876): 448 .

45. Daniel Noble, The Human Mind in Its Relations with the Brain and Nervous System (London: John Churchill, 1858), 90. The concept was also discussed by French physician Fahet, who attributed it to 'an eminent neurologist': M. Fahet, "On some of the Latent Causes of Insanity," excerpts (translated) from Leçons Cliniques de Médicine Mentale, Paris, 1854, Journal of Psychological Medicine and Mental Pathology 7 (1854): 163.

46. Thomas Laycock, "Reflex, Automatic and Unconscious Cerebration: A History and a Criticism," Journal of Mental Science 21 (1876): 477-498.

47. Quick, "Techniques of Life," 81-128.

48. William Benjamin Carpenter, Principles of Human Physiology (London: John Churchill, 1842), 229.

49. Carpenter, Principles of Human Physiology, 228.

50. Carpenter, Principles of Human Physiology, 228.

51. William Benjamin Carpenter, Principles of Human Physiology, 5th ed. (London: John Churchill, 1855), 549.

52. Carpenter, Principles of Human Physiology, 5th ed., 584. Cf. Alexander Bain's discussion of the relationship between emotion and volition. Bain was particularly concerned with the ability to control external manifestations of emotions, such as facial expressions and bodily gestures. Such 'voluntary' manifestations of emotion could, he suggested, be restrained or suppressed by volitional control, whereas 'involuntary' manifestations, such as blushing, could not. Alexander Bain, The Emotions and the Will (London: John W. Parker and Son, 1859), esp. 14-15 and Chapter 4, "Control of Feelings and Thought".

53. Two decades later, Carpenter still retained a belief in a will independent from and superior to emotional automatism: William Benjamin Carpenter, Principles of Mental Physiology (London: Henry S. King, 1874), 26.

54. See Chapter 4.

55. Carpenter, Principles of Human Physiology, 5th ed., 553.

56. Laycock made extensive use of comparative anatomy and physiology throughout his first monograph. 
57. Jacyna, "Somatic Theories of Mind," 237. 'Epilepsy' was at this time a term broadly applied to fits and convulsions believed to have a physical basis. While a relatively common feature described in asylum patients, epilepsy was generally not in itself a considered a sign or a form of insanity by British physicians. A helpful illustration of mid-century conceptions of epilepsy can be found in John Hitchman, "On Epilepsy," Provincial Medical and Surgical Journal (1852): 5-9.

58. By this term, Laycock meant 'nerves of the organs'.

59. Laycock, Nervous Diseases, 97-98.

60. From 'sensorium' or 'sensorium commune', a term that can be traced back to eighteenth-century physician Jiří Procháska, who used it to describe the point of connection between sensory and motor activity-where one triggered the other. Laycock's use of the term should, however, be distinguished from Procháska's, as the former used it to describe the nerves of sensation at the core-i.e. the brain-as opposed to the periphery; in short, 'the central...termination of a nerve'. Laycock, Nervous Diseases, 98. See also e.g. Müller, Elements, 937. For Procháska's use of the term, see Clarke and Jacyna, Neuroscientific Concepts, 105-106.

61. Laycock, Nervous Diseases, 113-114. Emphasis added.

62. Richard von Krafft-Ebing, Lebrbuch der Psychiatrie auf klinischer Grundlag: für practische Ärzte und Studirende, 5 Aufl. (Erlangen: Ferdinand Enke, 1893), 308; Thomas S. Clouston, Clinical Lectures on Mental Diseases London: J \& A Churchill, 1883): 32; Henry Maudsley, The Pathology of Mind: A Study of Its Distempers, Deformities, and Disorders, 4th ed. (London: Macmillan, 1895), 167.

63. Laycock, Nervous Diseases, 195.

64. Laycock, "On the Reflex Function of the Brain," 301.

65. Laycock, "On the Reflex Function of the Brain," 302.

66. Laycock, "On the Reflex Function of the Brain," 303. Emphasis in original.

67. Danziger, "Psycho-Physiology," 127.

68. Laycock, "On the Reflex Function of the Brain," 304.

69. William Senhouse, "The Physiology of the Human Brain," Journal of Psychological Medicine and Mental Pathology 3 (1850): 381-382. For the history of perceptions of the two hemispheres in modern science, see Anne Harrington, Medicine, Mind, and the Double Brain: Studies in NineteenthCentury Thought (Princeton, NJ: Princeton University Press, 1989).

70. Senhouse, "The Physiology of the Human Brain," 383.

71. James G. Davey, On the Nature and Proximate Cause of Insanity (London: John Churchill, 1853), 27-28. Emphasis in original.

72. In the mid-1800s, 'neurine' referred to nervous tissue (OED). By 'cineritious neurine' Davey meant the grey matter of the brain. 
73. James G. Davey, "Lectures on Insanity: Lecture III," Association Medical Journal 3, No. 140 (1855): 831.

74. Michael Clark, "Morbid Introspection": Unsoundness of Mind, and British Psychological Medicine, c. 1830-c.1900," in The Anatomy of Madness: Essays in the History of Psychiatry, Vol. III: The Asylum and Its Psychiatry, eds. William F. Bynum, Roy Porter, and Michael Shepherd, 71-101 (London: Routledge, 1988).

75. Clark, "Morbid Introspection," 73.

76. Clark, "Morbid Introspection," 73-80.

77. Clark, "Morbid Introspection," 75.

78. See Chapter 5.

79. James F. Duncan, Popular Errors on the Subject of Insanity Examined and Exposed (London: John Churchill, 1853), 14-15.

Open Access This chapter is licensed under the terms of the Creative Commons Attribution 4.0 International License (http://creativecommons.org/licenses/ by $/ 4.0 /$ ), which permits use, sharing, adaptation, distribution and reproduction in any medium or format, as long as you give appropriate credit to the original author(s) and the source, provide a link to the Creative Commons license and indicate if changes were made.

The images or other third party material in this chapter are included in the chapter's Creative Commons license, unless indicated otherwise in a credit line to the material. If material is not included in the chapter's Creative Commons license and your intended use is not permitted by statutory regulation or exceeds the permitted use, you will need to obtain permission directly from the copyright holder.

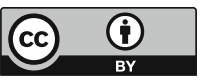

